\title{
Effect of incorporation of 2-tert-butylaminoethyl methacrylate on flexural strength of a denture base acrylic resin
}

\author{
André Gustavo PALEARI', Juliê MARRA', Ana Carolina PERO², Larissa Santana RODRIGUEZ ${ }^{3}$, \\ Adhemar RUVOLO-FILHO ${ }^{4}$, Marco Antonio COMPAGNONI ${ }^{5}$
}

\begin{abstract}
1- DDS, MSc, Department of Dental Materials and Prosthodontics, Araraquara Dental School, São Paulo State University (UNESP), Araraquara, SP, Brazil. 2- DDS, PhD, Department of Dental Materials and Prosthodontics, Araraquara Dental School, São Paulo State University (UNESP), Araraquara, SP, Brazil. 3- DDS, Department of Dental Materials and Prosthodontics, Araraquara Dental School, São Paulo State University (UNESP), Araraquara, SP, Brazil.

4- PhD, Associate Professor, Department of Chemistry, São Carlos Federal University (UFSCAR), São Carlos, SP, Brazil.

5- DDS, PhD, Full Professor, Department of Dental Materials and Prosthodontics, Araraquara Dental School, São Paulo State University (UNESP), Araraquara, SP, Brazil.
\end{abstract}

Corresponding address: Dr. Marco Antonio Compagnoni - Departamento de Materiais Odontológicos e Prótese - Faculdade de Odontologia de Araraquara - UNESP - Rua Humaitá 1680 - 14801-903 - Araraquara, SP - Brazil - Phone/Fax: +55-16-3301-6411 / +55-16-3301-6406 - e-mail: compagno@foar.unesp.br

Received: July 07, 2009 - Modification: September 09, 2009 - Accepted: February 16, 2010

\section{ABSTRACT}

\begin{abstract}
Dolymethyl methacrylate (PMMA) resins have commonly been used as a denture base material. However, denture bases may act as a reservoir for microorganisms and contribute to oral diseases in denture wearers. It is hypothesized that the 2-tertbutylaminoethyl methacrylate (TBAEMA) incorporated to acrylic resins should have antimicrobial activity related to the presence of amino groups on acrylic resin surface. Objectives: The objectives of this study were to evaluate the presence of amino groups on acrylic resin surface and the influence on flexural strength after incorporation of TBAEMA. Material and Methods: Six groups were divided according to the concentration of TBAEMA incorporated to acrylic resin (Lucitone 550): 0, 0.5, 1.0, 1.5, 1.75 and 2\%. Specimens surface were evaluated by Electron Spectroscopy for Chemical Analysis (ESCA) to detect the presence of amino groups, represented by nitrogen ratios. Flexural strength of the specimens was tested and results were analyzed by ANOVA and Tukey's test $(\alpha=0.05)$. Results: Different nitrogen ratios were observed on specimen surfaces: $0,0.13,0.74$, $0.66,0.92$ and $0.33 \%$ for groups $0,0.5,1.0,1.5,1.75$, and $2 \%$, respectively. Significant differences were found for flexural strength $(p<0.001)$. The mean flexural strength values were $98.3 \pm 3.9,93.3 \pm 3.2,83.9 \pm 2.1,82.8 \pm 5.2,71.2 \pm 5.1$ and $17.3 \pm 3.2 \mathrm{MPa}$ for groups $0,0.5,1.0,1.5,1.75$, and $2 \%$, respectively. Conclusion: Within the limitations of this study, the incorporation of TBAEMA results in the presence of the potentially antimicrobial amino groups on specimen surfaces, but affect the flexural strength, depending on the concentration of TBAEMA.
\end{abstract}

Key words: Acrylic resins. Local anti-infective agents. Mechanical stress. Surface properties.

\section{INTRODUCTION}

Poly (methyl methacrylate) resins have dominated the denture base market for over 50 years ${ }^{19}$. It is known that denture bases may act as a reservoir of microorganisms and contribute to oral diseases, such as denture stomatitis, a chronic inflammatory response in the oral mucosa, in complete denture wearers $3,6,11,25$. It has a multifactorial etiology, and C. albicans is reported as the primary etiologic agent ${ }^{20}$.

There is great evidence indicating that Candida is able to adhere to acrylic resin dentures. This is the first step that may lead to the development of the infectious process and that may ultimately result in varying degrees of denture stomatitis on the adjacent mucosa ${ }^{16}$.

To avoid the proliferation of microorganisms on the denture base resin surface, some authors have incorporated antifungal or antiseptic substances into denture base resins ${ }^{1,5,15,17,18,23}$. However, problems 
can arise due to release of those substances from the resins, such as toxic effects on the oral mucosa, damage to mechanical properties when polymerized with denture base resin and loss of effectiveness over time ${ }^{8,17}$.

Ottersbach and Kossmann ${ }^{13}$ (2002) reported that poly (2-tert-butylaminoethyl) methacrylate [poly(TBAEMA) powder] is a polycationic substance that contains pendant amino groups that act as an efficient contact biocide. Some authors incorporated this substance into polyethylene to achieve a product with antimicrobial activity $7,12,22,24$. In those cases, mere contact of bacteria with the polymer surface is sufficient to provide the biocide effect. Similarly, the 2-tert-butylaminoethyl methacrylate (TBAEMA) monomer is a liquid substance that contains amino groups in its composition. It has been hypothesized that TBAEMA incorporated into acrylic resins might also inhibit microorganism growth on the denture surface. It would be possible because pendant amino groups might arise on acrylic resin surface, which would display antimicrobial activity and become a possible treatment for the inhibition of biofilm formation.

Considering that complete dentures are subjected to repeated flexural forces, it is important to evaluate the mechanical properties of acrylic resins after TBAEMA incorporation. The flexural strength of acrylic resins is a property that is challenged every time the denture undergoes cyclic functional deformation ${ }^{3}$. The evaluation of the flexural strength could be valuable to direct future studies, because it could indicate whether the incorporation of TBAEMA damages the typical resistance of the denture. The objective of this study was to evaluate the presence of amino groups on acrylic resin surface and the influence on flexural strength after the incorporation of TBAEMA.

\section{MATERIAL AND METHODS}

In this study, a control group (unmodified acrylic resin) and 5 experimental groups of acrylic resin modified with TBAEMA (batch number 126031013; Degussa Creavis, Marl, Germany) in different ratios were evaluated (Table 1 ). Denture base resin Lucitone 550 (batch number liquid 395100 and powder 66655; Dentsply Ind. e Com. Ltda, Petrópolis, RJ, Brazil) was used for all groups. Each group (Table 1) was analyzed by XPS-ESCA (Kratos, Manchester, UK) to evaluate the presence of amino groups, represented by nitrogen ratios and submitted to flexural strength testing in a material testing system machine (Model 810; MTS System Corp, Edden Praire, MN, USA).

\section{XPS-ESCA analysis}

Specimens for XPS-ESCA analysis were prepared by investing glass slides measuring $25 \mathrm{~mm} \times 75$ $\mathrm{mm}$ in metal flasks supported by dental stone (Herodent; Vigodent S.A. Ind. Com., Rio de Janeiro, RJ, Brazil). After the invested material had set, the flasks were separated (Figure 1) and the mixtures (Table 1 ) were placed between glass slides to provide thin specimens (80-120 $\mu \mathrm{m})$ with uniform size and smooth surface. Mixtures were then packed and polymerized in an automatic polymerization tank (Solab Equipamentos para Laboratórios Ltda., Piracicaba, SP, Brazil) according to the cycle recommended by the Lucitone 550 manufacturer (water bath: $90 \mathrm{~min}$ at $73^{\circ} \mathrm{C}$ and then boiling water for $30 \mathrm{~min}$ ). One specimen was obtained for each group. After processing, excess acrylic resin was trimmed from all specimens with a bur (Maxi-Cut; Lesfils de August Malleifer SA, Ballaigues, Switzerland).

XPS-ESCA was utilized to analyze the presence of nitrogen ratios on specimen's surface, with a Kratos XSAM HS spectrometer (Kratos). The nitrogen ratios detected on specimen's surface can be considered chemically similar to the percentage of amino groups on the specimen surfaces. Photoelectrons were excited by $\mathrm{MgKa}$ radiation (1253.6 eV, $52 \mathrm{~W}$ ) and the binding energies of the measured photoelectron peaks were calibrated by the $\mathrm{C} 1 \mathrm{~s}$ peak of hydrocarbon contamination at a binding energy of $285.0 \mathrm{eV}$.

\section{Flexural strength}

Specimens for flexural strength analysis were prepared by investing metal patterns, measuring 67 $\mathrm{mm} \times 12 \mathrm{~mm} \times 5.3 \mathrm{~mm}$ in metal flasks. To facilitate removal from the flask, the master patterns were individually invested in high-viscosity silicone (Zetalabor; Zhermack S.p.A., Badia Polesine, Rovigo, Italy) and were then further supported by dental stone (Herodent; Vigodent S/A Ind. Com.) within the flasks. After the invested material had set, the flasks were separated and the master pattern was removed from the silicone mold ${ }^{2}$. Mixtures of acrylic resin (Table 1 ) were then packed and polymerized in an automatic polymerization tank according to the cycle recommended by the Lucitone 550 manufacturer.

Ten specimens were obtained for each group. The specimens were polished in a polishing machine (Arotec Ind. e Com. Ltda, Cotia, SP, Brazil) to a final dimension of $65 \mathrm{~mm} \times 10 \mathrm{~mm} \times 3.3 \mathrm{~mm}$, according to the International Organization for Standardization (ISO/FDIS 1567) ${ }^{9}$. Each specimen surfaces were finished with 280, 320-, 400- and 600 -grit wet-dry abrasive paper (Norton; SaintGobain Abrasivos Ltda, Vinhedo, SP, Brazil). Specimen dimensions were verified using a digital 
caliper (Mitutoyo, Hiroshima, Japan). All specimens were stored in distilled water at $37^{\circ} \mathrm{C}$ for $50 \pm 2 \mathrm{~h}$ before testing ${ }^{2,9}$.

The flexural strength of the groups was measured using a 3-point bending test in a material testing system machine (Model 810, MTS System Corp, Eden Prairie, MN, USA) at a crosshead speed of 5 $\mathrm{mm} / \mathrm{min}$. The flexural strength was calculated using the formula: $F S=3 W L / 2 b d^{2}$, where FS is flexural strength, $W$ is the maximum load before fracture, $L$ is the distance between supports ( $50 \mathrm{~mm}), b$ is the specimen width and $d$ is the specimen thickness. Statistical analysis was performed using a one-way ANOVA and Tukey's test for post-hoc comparisons. All analyses were performed at $\alpha=0.05$, using the SPSS for Windows software (version 12.0.0, SPSS Inc., Chicago, IL, USA).

\section{RESULTS}

Table 2 shows the nitrogen ratios on specimen's surfaces (\%) for all groups. The results showed that the incorporation of TBAEMA into acrylic resin resulted in different nitrogen ratios on specimen's surfaces. The addition of $1.75 \%$ of TBAEMA to acrylic resin showed the highest nitrogen ratio $(0.92 \%)$. Among the experimental specimens, the lowest nitrogen ratio was observed when $0.5 \%$ of TBAEMA was incorporated into acrylic resin $(0.13 \%)$. The control specimen showed no detectable amount of nitrogen.

Mean values and standard deviations for flexural strength are shown in Figure 2. ANOVA showed statistically significant differences among the groups $(p<0.001)$. Tukey's test showed no statistically significant difference between unmodified acrylic

Table 1- Groups evaluated in the study, according to the proportion of powder, liquid and TBAEMA

\begin{tabular}{cccc}
\hline $\begin{array}{c}\text { Group } \\
\text { (\%TBAEMA) }\end{array}$ & $\begin{array}{c}\text { Powder }(\mathbf{g}) \\
\text { (PMMA) }\end{array}$ & $\begin{array}{c}\text { Liquid }(\mathbf{m L}) \\
\text { (MMA and EGDMA) }\end{array}$ & TBAEMA $(\mathbf{m L})$ \\
\hline $0.00 \%$ & 21 & 10 & 0 \\
$0.50 \%$ & 21 & 9.950 & 0.05 \\
$1.00 \%$ & 21 & 9.900 & 0.100 \\
$1.50 \%$ & 21 & 9.850 & 0.150 \\
$1.75 \%$ & 21 & 9.825 & 0.175 \\
$2.00 \%$ & 21 & 9.800 & 0.2 \\
\hline
\end{tabular}

TBAEMA, 2-tert-butylaminoethyl methacrylate; PMMA, poly (methyl methacrylate); MMA, methyl methacrylate; EGDMA, ethylene glycol dimethacrylate

Table 2- Nitrogen ratios on specimen's surface

\begin{tabular}{cc}
\hline Group & Nitrogen ratios (\% atomic) \\
\hline $0.00 \%$ & 0 \\
$0.50 \%$ & 0.13 \\
$1.00 \%$ & 0.74 \\
$1.50 \%$ & 0.66 \\
$1.75 \%$ & 0.92 \\
\hline $2.00 \%$ & 0.33 \\
\hline
\end{tabular}

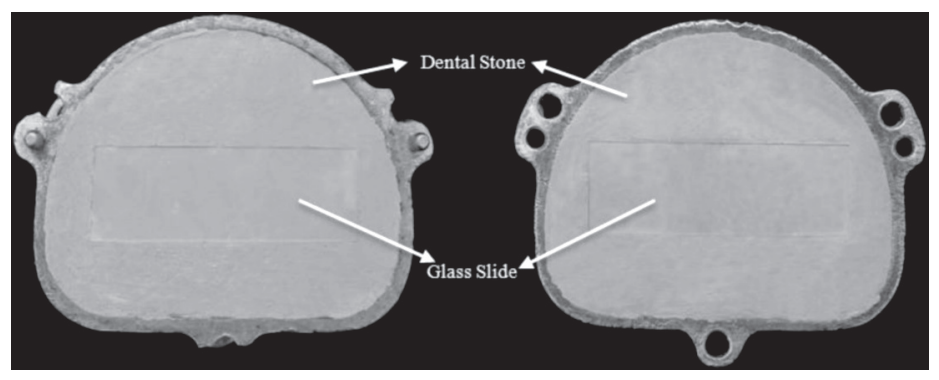

Figure 1- Glass slides invested in metal flasks supported by dental stone 


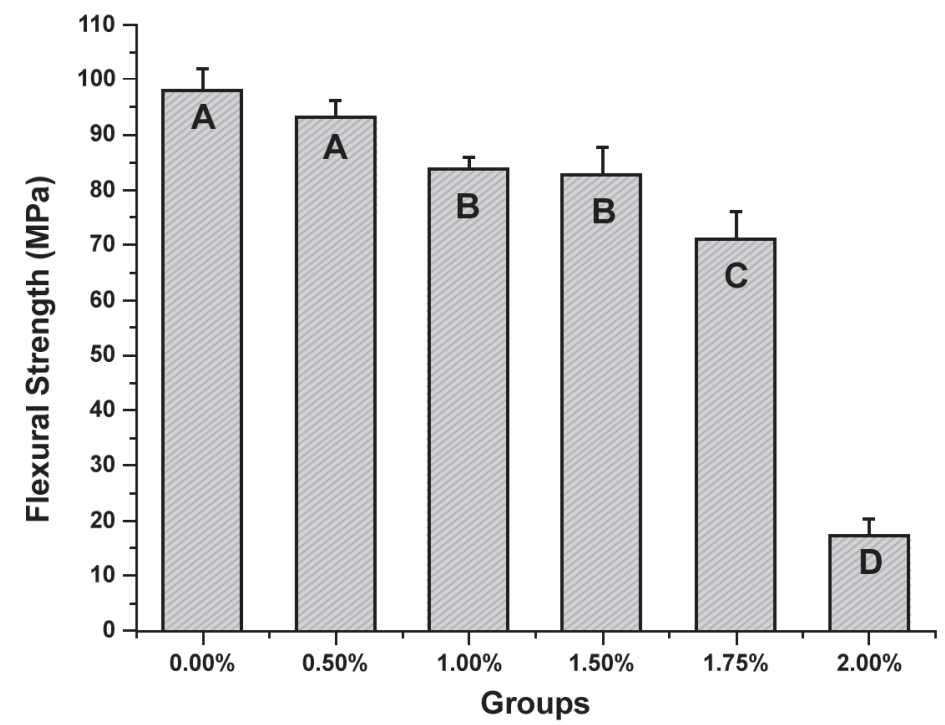

Figure 2- Mean flexural strength values for all groups (bars represent standard deviations). The same capital letters indicate no statistically significant difference. (Tukey's test, $\mathrm{P}<0.05)$

resin (control) (98.26 $\pm 3.9 \mathrm{MPa})$ and $0.5 \%$ TBAEMA group (93.32 $\pm 3.24 \mathrm{MPa})$. The $1.0 \%(83.92 \pm 2.08$ $\mathrm{MPa})$ and $1.5 \%(82.85 \pm 5.17 \mathrm{MPa})$ TBAEMA groups showed no statistically significant difference between them. The addition of $1.75 \%$ of TBAEMA demonstrated intermediate results (71.19 \pm 5.08 $\mathrm{MPa})$. The lowest flexural strength value was observed for $2 \%$ TBAEMA group (17.29 $\pm 3.24 \mathrm{MPa})$.

\section{DISCUSSION}

Incorporating substances that could show antimicrobial activity into acrylic resins is a current trend in order to avoid denture stomatitis or related oral diseases ${ }^{1,5,15,17,18,23}$.

In this study, TBAEMA was incorporated into acrylic resin (Lucitone 550). The literature is scarce about this subject, since no study was found describing the incorporation of TBAEMA in polymers for dental applications. However, acrylic resin could possibly show antimicrobial activity if amino groups were found on it surface after incorporation of TBAEMA, in view of the fact that there is an association between amino groups on surfaces and antimicrobial activities $^{12-14,22,24}$.

Different nitrogen ratios were found on specimen's surface. The nitrogen ratios detected on specimen's surfaces can be considered chemically similar to the percentage of amino groups. These results are important because the literature presents that polymers functionalized with pendant amino groups display high antimicrobial activity 12-14,22,24. Consequently, acrylic resin containing TBAEMA could show antimicrobial activity, although these findings cannot be extrapolated to clinical use without further investigations.

In general, an increase in the atomic percentages of nitrogen was associated with higher concentrations of TBAEMA in acrylic resin. The resin containing $2 \%$ TBAEMA showed lower values with regard to the percentage of amino groups than the others. This might have occurred due to a possible decrease in the degree of conversion of acrylic resin, which may result in less free nitrogen on specimen surfaces.

Flexural strength results demonstrated that the incorporation of TBAEMA to acrylic resin promoted an increasing reduction in this property. A decrease in denture base acrylic resin flexural strength can result in greater fracture incidence by impact or oclusal forces ${ }^{4,21}$. However, the values found for all groups, except for the $2 \%$ group, are within the minimum value ( $65 \mathrm{MPa}$ ) recommended by the ISO 1567 standard $^{9}$.

It seems that acrylic resin may soften by the incorporation of TBAEMA and flexural properties dramatically go down with incorporations higher than $1.75 \%$. A possible reason for that effect is the incomplete polymerization process of acrylic resin after the incorporation of TBAEMA and a large amount of residual monomer. Jagger ${ }^{10}$ (1978) stated that residual monomer adversely affects the mechanical properties by means of plasticizing effect. Moreover, the results of this study are consistent with previous reports, which found that the flexural strength value decreased with the increase in antimicrobial agents added to acrylic resin ${ }^{1,3,5,23}$. Shibata, et al. ${ }^{23}$ (2007) affirmed that the degree of conversion of acrylic resin might be adversely affected after addition of other material, which would lead to an increase in residual monomer amount on acrylic resin. Taken together, the decrease in the degree of conversion of acrylic resin and the increase in residual monomer amount would cause a loss in mechanical properties of acrylic resin. Dhir, et al. ${ }^{5}$ (2007) supposed that the decrease in flexural strength could be associated with the dilution of components of the liquid, such as the cross linking 
agent ethylene glycol dimethacrylate (EGDMA). Cunha, et al. ${ }^{4}$ (2009) explained that the lower mean flexural strength and modulus of elasticity of acrylic resin after incorporation of fluoroalkyl methacrylates resides in the intermolecular interaction because the presence of this substance in methacrylic polymers results on different intermolecular distances among polymers chains.

This in vitro study has some limitations. Firstly, literature is scarce about this subject, since no study was found describing the incorporation of TBAEMA in products for dental applications. Additionally, just one commercial available heat-polymerized acrylic resin (Lucitone 550) was tested. It is possible that the incorporation of TBAEMA in another acrylic resin with different polymerization cycle, as microwavepolymerized or autopolymerized acrylic resins could not cause deleterious effects on its mechanical properties, as observed in this study. It would allow for higher concentrations of TBAEMA, and consequently higher amine ratios on acrylic resin surface.

Further studies are recommended to investigate the conversion degree of acrylic resin, quantify the amount of residual monomers and analyze physical, chemical and mechanical properties of acrylic resin after incorporation of TBAEMA. Furthermore, microbiological and cytotoxicity tests are required before these findings can be applied in clinical research, from the perspective that complete dentures with antimicrobial properties could improve the oral health of elderly patients.

\section{CONCLUSION}

The presence of amino groups on acrylic resin surface after the incorporation of TBAEMA indicates a possible antimicrobial activity. However, certain concentrations of TBAEMA can reduce the flexural strength of the tested resin.

\section{ACKNOWLEDGEMENTS}

The authors gratefully acknowledge the assistance of the Federal University of São Carlos with the ESCA analysis and FAPESP (2007/02008-8) for financial support.

\section{REFERENCES}

1- Addy M, Handley R. The effects of the incorporation of chlorhexidine acetate on some physical properties of polymerized and plasticized acrylics. J Oral Rehabil. 1981;8:155-63.

2- Barbosa DB, Souza RF, Pero AC, Marra J, Compagnoni MA. Flexural strength of acrylic resins polymerized by different cycles. J Appl Oral Sci. 2007;15:424-8.

3- Casemiro LA, Martins $\mathrm{CH}$, Pires-de-Souza FD, Panzeri $\mathrm{H}$. Antimicrobial and mechanical properties of acrylic resins with incorporated silver-zinc zeolite - part I. Gerodontology. 2008;25:187-94.
4- Cunha TR, Regis RR, Bonatti MR, Souza RF. Influence of incorporation of fluoroalkyl methacrylates on roughness and flexural strength of a denture base acrylic resin. J Appl Oral Sci. 2009;17:103-7.

5- Dhir G, Berzins DW, Dhuru VB, Periathamby AR, Dentino A. Physical properties of denture base resins potentially resistant to Candida adhesion. J Prosthodont. 2007;16:465-72.

6- Fermandes RA, Lovato-Silva $\mathrm{CH}$, Paranhos Hde F, Ito IY. Efficacy of three denture brushes on biofilm removal from complete dentures. J Appl Oral Sci. 2007;15:39-43.

7- Ignatova M, Voccia S, Gilbert B, Markova N, Cossement D, Gouttebaron R, et al. Combination of electrografting and atomtransfer radical polymerization for making the stainless steel surface antibacterial and protein antiadhesive. Langmuir. 2006;22:255-62. 8- Imazato S, Torii M, Tsuchitani Y, McCabe JF, Russell RR. Incorporation of bacterial inhibitor into resin composite. J Dent Res. 1994;73:1437-43.

9- International Organization for Standardization. ISO 1567: denture base polymers. $2^{\text {nd }}$ ed. Geneva: The Organization; 1998.

10- Jagger RG. Effect of the curing cycle on some properties of a polymethylmethacrylate denture base material. J Oral Rehabil. 1978; 5:151-7.

11- Lamfon H, Al-Karaawi Z, McCullough M, Porter SR, Pratten J. Composition of in vitro denture plaque biofilms and susceptibility to antifungals. FEMS Microbiol Lett. 2005;242:345-51.

12- Lenoir $S$, Pagnoulle $C$, Galleni $M$, Compère $P$, Jérôme $R$, Detrembleur $C$. Polyolefin matrixes with permanent antibacterial activity: preparation, antibacterial activity, and action mode of the active species. Biomacromolecules. 2006;7:2291-6.

13- Ottersbach P, Kossmann B. Eine neue Klasse von Bioziden. GIT Labor Fachzeitschrift. 2002;46:452-6.

14- Ottersbach P, Sosna F, inventors; Creavis Tech \& Innovation GMBH (DE). Antimikrobielle Zusatzstoffe. DE 100224532001 Mar. 15.

15- Park SE, Periathamby AR, Loza JC. Effect of surface-charged poly (methyl methacrylate) on the adhesion of Candida albicans. J Prosthodont. 2003;12:249-54.

16- Pereira-Cenci T, Del Bel Cury AA, Crielaard W, Ten Cate JM. Development of Candida-associated denture stomatitis: new insights. J Appl Oral Sci. 2008;16:86-94.

17- Pesci-Bardon C, Fosse T, Madinier I, Serre D. In vitro new dialysis protocol to assay the antiseptic properties of a quaternary ammonium compound polymerized with denture acrylic resin. Lett Appl Microbiol. 2004;39:226-231.

18- Pesci-Bardon C, Fosse T, Serre D, Madinier I. In vitro antiseptic properties of an ammonium compound combined with denture base acrylic resin. Gerodontology. 2006;23:111-6.

19- Phoenix RD, Mansueto MA, Ackerman NA, Jones RE. Evaluation of mechanical and thermal properties of commonly used denture base resins. J Prosthodont. 2004;13:17-27.

20- Pinto TM, Neves AC, Leão MV, Jorge AO. Vinegar as an antimicrobial agent for control of Candida spp. in complete denture wearers. J Appl Oral Sci. 2008;16:385-90.

21- Sato S, Cavalcante MR, Orsi IA, Paranhos HFO, Zaniquelli $O$. Assessment of flexural strength and color alteration of heatpolymerized acrylic resins after simulated use of denture cleansers. Braz Dent J. 2005;6:124-8.

22- Seyfriedsberger G, Rametsteiner Ka, Kern W. Polyethylene compounds with antimicrobial surface properties. Euro Polym J. 2006;42:3383-9.

23- Shibata T, Hamada N, Kimoto K, Sawada T, Sawada T, Kumada $\mathrm{H}$, et al. Antifungal effect of acrylic resin containing Apatite-coated TiO2 photocatalyst. Dent Mater J. 2007;26:437-44.

24- Thomassin JM, Lenoir S, Riga J, Jérôme R, Detrembleur C. Grafting of poly[2-(tert-butylamino)ethyl methacrylate] onto polypropylene by reactive blending and antibacterial activity of the copolymer. Biomacromolecules. 2007;8:1171-7.

25- Wilson J. The aetiology, diagnosis and management of denture stomatitis. Br Dent J. 1998;24;185:380-4. 